\title{
A Cell-Based Subtractive Panning Strategy for Selection of Conformation-Specific Single-Chain Variable-Fragment (Scfv) Against Dimerization Domain of EGFR
}

\section{Reza Valadan}

Mazandaran University of Medical Sciences

Mina Dabiri

Mazandaran University of Medical Sciences

Mohsen Tehrani

Mazandaran University of Medical Sciences

Gholamreza Hashemi Tabar

Ferdowsi University of Mashhad

Alireza Rafiei ( $\square$ alireza.rafiei96@yahoo.com)

Mazandaran University of Medical Sciences

\section{Research Article}

Keywords: EGFR, HER2, Dimerization domain, scFv, phage display

Posted Date: May 3rd, 2021

DOI: https://doi.org/10.21203/rs.3.rs-421317/v1

License: (c) (1) This work is licensed under a Creative Commons Attribution 4.0 International License.

Read Full License 


\section{Abstract \\ Background and Objective:}

Overexpression of the EGFR, from the ErbB receptor family, has been observed in several cancers and causes resistance to therapeutic antibodies, such as Herceptin. In this study, we produced a recombinant single-chain variable fragment (scFv) antibody against the EGFR dimerization domain.

\section{Methods}

The recombinant scFv was generated using a cell-based subtractive panning strategy. Subtractive panning was performed on genetically engineered VERO/EGFR cells and cancerous MDA-MB-468 cells. Phage cell-ELISA was used to monitor the binding of the selected scFvs to the dimerization domain of EGFR. Inhibition of EGFR and HER2 dimerization by the produced scFvs were finally evaluated using the dimerization inhibition test.

\section{Results}

PCR fingerprinting results showed a uniform digestion pattern following the third round of panning that confirmed the success of subtractive panning. Moreover, cell-ELISA validated the reactivity of the produced scFvs to EGFR after stimulation with EGF. The dimerization inhibition test showed the capacity of the scFvs to inhibit EGFR and HER2 dimerization.

\section{Conclusions}

Directed HER2 targeting showed to be more effective to target the functional domain of the cell receptor for the complete blockade of the intracellular signaling pathway. The subtractive panning strategy used in this study could control the process of directed selection of specific antibodies against the dimerization domain of EGFR. The selected antibodies might then be functionally tested for antitumor effects in both in vitro and in vivo studies.

\section{Introduction}

Resistance to monoclonal antibody (mAb) therapy is known as a major problem in ErbB familyexpressing tumors. Trastuzumab, a humanized recombinant anti-HER2 antibody, was the first FDAapproved mAb for the treatment in HER2 positive breast cancers; however, about $70 \%$ of patients do not respond to the treatment, and some others develop resistance within a year $(1,2)$. ErbB receptors (EGFR, HER2, HER3 and HER4) are structurally composed of three parts: an extracellular domain that binds to the ligand, a transmembrane domain, and an intracellular domain that also has tyrosine kinase properties. The extracellular part of the ErbB receptors consists of four domains (I, II, III \& IV). While EGFR 
is inactive, its domain II (dimerization domain) is hidden; after activation with the ligand, the dimerization domain is exposed which leads to homodimerization or heterodimerization $(3,4)$.

EGFR activates important signaling pathways, such as Ras/MAPK and PI3K/AKT pathways, and signaling cascade of phospholipase $C(P L C)$ /protein kinase $C(P K C)(5,6)$. ErbB family signaling pathways, especially EGFR signaling, have been dysregulated in a wide range of cancers (7).

Dysregulated EGFR expression could induce homo/hetrodimerization, notably with HER2. HER2 is unique in the ErbB family, because it is an orphan receptor, which is shown to be the preferred dimerization partner for EGFR (8).

Current strategy for the treatment for EGFR positive cancers is blockade of EGFR signaling pathway by using recombinant antibodies against the extracellular domain, as well as other drugs to block the intracellular domain tyrosine kinase activity $(9,10)$. In this regard, Cetuximab and Panitumumab have been developed against the EGFR receptor in colorectal cancer, but neither of them could bind to the dimerization domain of the receptor and does not hinder heterodimerization $(11,12)$.

Single-chain fragment variables (scFvs) have been introduced for several advantages, such as fast clearance from the blood, rapid penetration in tumor microenvironment due to their small size, the potential of carrying drugs and toxins, and binding to the epitope with a high affinity (13). Moreover, the production of scFv is rather easy; it can be expressed by several expression systems, such as yeast, plant, and bacteria, where the bacterial expression systems have been used more than the others (14).

In this study, using the phage display technique, we produced a recombinant scFv against the EGFR dimerization domain, in addition to targeting EGFR, it can hinder its dimerization with other ErbB family receptors, especially HER2, and block signal pathways resulting in tumor cell apoptosis.

\section{Materials And Methods}

\section{Cell Culture}

Cell lines used in this study were as follows VERO, MDA-MB-468, VERO expressing EGFR (VERO/EGFR), VERO expressing HER2 (VERO/HER2), and VERO expressing both EGFR and HER2 (VERO/EGFR/HER2). VERO and MDA-MB-468 were obtained from the Pasteur Institute of Iran (Tehran, Iran) and maintained in the appropriate media recommended by the provider. VERO/HER2 cell line has been established previously (15-17).

VERO/EGFR cells were generated from transfected VERO cells using the linearized plasmid pCMVencoding full-length EGFR. VERO/EGFR/HER2 was also generated through transfection of VERO/EGFR cells with pCVN-encoding full-length HER2. The selection of the cells was carried out via culture in the presence of $500 \mu \mathrm{g} / \mathrm{ml}$ hygromycin for VERO/EGFR, and $500 \mu \mathrm{g} / \mathrm{ml}$ hygromycin and $500 \mu \mathrm{g} / \mathrm{ml} \mathrm{G} 418$ for VERO/EGFR/HER2. Both cell lines were cultured in an appropriate medium in $250 \mu \mathrm{g} / \mathrm{ml}$ maintenance dose of hygromycin and G418. 


\section{Library preparation}

The Tomlinson $\mathrm{J}$ and I phage display antibody libraries (Source BioScience, UK) were used to select antibody fragments against the extracellular subdomain II (dimerization arm) of EGFR expressed on the surface of VERO/EGFR cells. These are semisynthetic phage libraries based on a single human framework with side-chain diversity incorporated at positions in the antigen-binding site. Stocks of recombinant M13 phages displaying plll-scFv fusion on their surface were prepared, according to the recommended protocol (16). Briefly, aliquots of each library were cultured in $200 \mathrm{ml}$ of 2xTY medium supplemented with $1 \%$ glucose and $100 \mu \mathrm{g} / \mathrm{ml}$ ampicillin at $\mathrm{OD}_{600}=0.4$. Approximately $2 \times 10^{11}$ of M13K07 helper phages were added to $50 \mathrm{ml}$ of the culture medium and incubated at $37^{\circ} \mathrm{C}$ in a water bath for $30 \mathrm{~min}$. Bacterial pellets were collected by centrifugation at $3300 \times \mathrm{g}$ for $30 \mathrm{~min}$ and the pellets were then resuspended in $100 \mathrm{ml}$ of $2 X$ TY medium supplemented with $0.1 \%$ glucose, $100 \mu \mathrm{g} / \mathrm{ml}$ ampicillin, and $50 \mu \mathrm{g} / \mathrm{ml}$ kanamycin. Recombinant phages were precipitated from the overnight culture with PEG/NaCl solution (20\% Polyethylene glycol $6000,2.5 \mathrm{M} \mathrm{NaCl})$.

\section{Subtractive panning on the cells}

The first round of panning was performed on MDA-MB-468, a cancer cell line overexpressing EGFR, to reduce non-specific bindings. The process of antibody selection is schematically shown in Figure 1.

Each library $\left(\sim 10^{12} \mathrm{pfu} / \mathrm{ml}\right)$ was incubated with the MDA-MB-468 cell line for 2 hours at room temperature with gently rotating. The cells were then pelleted by centrifugation at $140 \times \mathrm{g}$ for $20 \mathrm{~min}$, and the supernatant was moved to a new tube. The next round was performed on EGF-stimulated $(60 \mathrm{ng} / \mathrm{ml})$ and then -non-stimulated VERO/EGFR cells (19). The cells were pelleted and washed twice with HEPES washing buffer. The bound phages were then eluted with $1 \mathrm{ml}$ glycine buffer $(\mathrm{pH}=2.2)$ and then used for reinoculation of exponentially growing TG1 bacteria. Next, $20 \mathrm{ml}$ of 2xTY-Amp-Glu medium was inoculated with 10 to $20 \mu \mathrm{l}$ bacterial suspension to yield an $\mathrm{OD}_{600}=0.1$, and grown at $37^{\circ} \mathrm{C}$ and $140 \times \mathrm{g}$ at $\mathrm{OD}_{600}=0.5$. The bacteria were then inoculated with $\mathrm{M} 13 \mathrm{~K} 07$ helper phage in a multiplicity of infection (MOI: phage/bacteria) of 10 to 20 for $30 \mathrm{~min}$ at $37^{\circ} \mathrm{C}$ in a water bath. Bacteria were pelleted and resuspended in $100 \mathrm{ml} 2$ XTY containing $100 \mathrm{mg} / \mathrm{ml}$ ampicillin and $50 \mathrm{mg} / \mathrm{ml}$ kanamycin culture medium and incubated overnight at $30^{\circ} \mathrm{C}$ on a shaker. The same procedure was performed for the VERO/EGFR cell line for two more rounds of panning.

\section{PCR and fingerprinting}

To evaluate the results of the selection process of single-chain antibodies, variety in selected clones was examined by PCR and fingerprinting at the end of the last round of panning. PCR was carried out on several clones using two primers, LMB3: CAGGAAACAGCTATGAC and pHEN: CTATGCGGCCCCATTCA. 
Positive samples were digested by $B s t M$ restriction enzyme overnight at $37^{\circ} \mathrm{C}$ and loaded on a $2 \%$ agarose gel.

\section{Polyclonal phage cell ELISA}

To confirm binding of the pool of isolated phages to their ligands on the cells, a phage ELISA was performed with EGF-stimulated and -non-stimulated VERO/EGFR cells, using phages from all three rounds of panning. Approximately $7 \times 10^{3}$ VERO/EGFR cells were seeded in each well of 96-well culture plates (SPL, South Korea) one day before the experiment. The experiment was performed in triplicate. Cells were washed twice with cold phosphate-buffered saline (PBS) and blocked with $200 \mu \mathrm{l} \%$ bovine serum albumin (BSA) for 1 hour at room temperature. Then, $100 \mu \mathrm{l}$ of the polyclonal phage particles from each round of selection was added to each well and incubated for 2 hours at room temperature. The wells were washed three times with $200 \mu \mathrm{l}$ tris-buffered saline, $0.1 \%$ tween 20 (TBST), then incubated with $100 \mu \mathrm{l}$ of 1:5000 dilutions of HRP-conjugated anti-M13 antibody (Amersham Pharmacia, US) in 2\% blocking buffer for 1 hour at room temperature. Finally, the wells were washed three times with TTBS and incubated with tetramethylbenzidine (TMB) solution (Sigma-Aldrich) for $15 \mathrm{~min}$ at room temperature. The reactions were stopped by $3 \mathrm{~N} \mathrm{HCl}$, and the absorbance was read at $450 \mathrm{~nm}$ on an ELISA plate reader (Organon-Teknika, The Netherlands).

\section{Dimerization inhibition test}

Dimerization inhibition test was performed with phages obtained from each round of selection. The VERO/EGFR/HER2 cell line was serum-starved for 24 hours, and then cells were detached by a cell scraper and washed with PBS. The cells were stimulated with $60 \mathrm{ng} / \mathrm{ml}$ of EGF for $30 \mathrm{~min}$ on ice, following by incubation with selected phages from each round of panning for $30 \mathrm{~min}$. Crosslinking of HER2 and EGFR was performed with a cell membrane-impermeable protein crosslinking agent, sulfosuccinimidyl (bis) substrate, (Thermo Fisher Scientific, Inc., MA, USA), according to the manufacturer's instructions. Briefly, the cells were washed twice with ice-cold PBS and incubated with freshly prepared bis substrate at room temperature for $30 \mathrm{~min}$. Cells were lysed using a radioimmunoprecipitation assay (RIPA) buffer (Santa Cruz Biotechnology, Santa Cruz, CA, USA) containing $2 \mathrm{mM}$ phenylmethylsulfonyl fluoride (PMSF), $10 \mathrm{~mL}$ of protease inhibitor cocktail, and $1 \mathrm{mM}$ sodium orthovanadate.

The total cell lysate was immunoprecipitated, using mouse anti-EGFR (Clone D8, Santa Cruz Biotechnology) antibody. Briefly, $500 \mu \mathrm{g}$ of total cell lysate was incubated with protein $\mathrm{A} / \mathrm{G}$ plus agarose in the presence of $5 \mu \mathrm{g}$ of anti-EGFR antibody overnight at $4{ }^{\circ} \mathrm{C}$ with gentle shaking. The antigen-antibody complexes were then pelleted and washed 4 times. The complex was detached using loading buffer (62.5 $\mathrm{mM}$ Tris $\cdot \mathrm{Cl}, \mathrm{pH} 6.8,2 \% \mathrm{w} / \mathrm{v}$ SDS, $2 \%$ v/v glycerol $0.1 \% \mathrm{w} / \mathrm{v}$ bromphenol blue, and $300 \mathrm{mM} 2-$ mercaptoethanol) and heated at $75^{\circ} \mathrm{C}$ for $10 \mathrm{~min}$. 
To show the ability of selected scFv to inhibit EGFR homodimerization and EGFR/HER2 heterodimerization, the anti-EGFR immunoprecipitated proteins were separated under a denaturing and reducing SDS-PAGE and then transferred to Polyvinylidene difluoride (PVDF) membranes (Santa Cruz Biotechnology) in a tank transfer system (Bio-Rad, CA, USA) at $100 \mathrm{~V}$ for $60 \mathrm{~min}$. Membranes were then separately probed with anti-EGFR and anti-HER2 as the primary antibodies, and the goat anti-mouse conjugated HRP as the secondary antibody. The blots were developed with the ECL kit (Parstous Biotec, Mashhad, Iran) for 5 min and imaged by the G:BOX imaging system (Syngene, Cambridge, UK).

\section{Production and purification of phage free scFv}

Soluble scFv was produced to evaluate the function of the selected antibody pools. To do this, $100 \mu$ l of the eluted phages from each round of selection were incubated with $2 \mathrm{ml}$ of exponentially growing $\mathrm{HB} 2151$ bacteria $\left(\mathrm{OD}_{600}=0.4\right)$ for $30 \mathrm{~min}$ at $37^{\circ} \mathrm{C}$ in a water bath. Then, the bacteria were pelleted and plated on the TYE-Amp-Glu medium. Bacterial colonies were then scraped by a spatula. Then, $50 \mu \mathrm{l}$ of each phage pool was inoculated in $50 \mathrm{ml} 2 \mathrm{XTY}$-Amp and incubated with shaking at $37^{\circ} \mathrm{C}$ for approximately 6 hours until $\mathrm{OD}_{600}$ reached 0.8 to 1 . Isopropyl $\beta$-D-1-thiogalactopyranoside (IPTG) was added to a final concentration of $1 \mathrm{mM}$ and incubated with shaking at $30^{\circ} \mathrm{C}$ overnight. Bacterial were then pelleted and dissolved in $2 \mathrm{ml}$ of hyper-osmotic lysis solution containing $50 \mathrm{mM}$ Tris, $20 \%$ saccharose, and $1 \mathrm{mM}$ EDTA at $\mathrm{pH}$ 8. Cell debris was pelleted by centrifugation at $20,000 \times \mathrm{g}$ for $30 \mathrm{~min}$ at $4^{\circ} \mathrm{C}$, and the supernatant containing the desired antibodies were collected and stored at $-20^{\circ} \mathrm{C}$ for subsequent use.

Soluble scFvs were separated from the protein mixture using HisTrap HP affinity chromatography with an ÄKTA purifier. Briefly, the HisTrap ${ }^{\mathrm{TM}} \mathrm{HP}$ column was equilibrated with the binding buffer, containing 50 $\mathrm{mM}$ Tris, $1 \mathrm{M} \mathrm{NaCl}$, and $40 \mathrm{mM}$ Imidazole, and then the protein mixture was injected into the column. The His-tagged recombinant protein was eluted with the elution buffer, containing $50 \mathrm{mM}$ Tris, $500 \mathrm{mM} \mathrm{NaCl}$, and $500 \mathrm{mM}$ imidazole at $\mathrm{pH} 8$, fractions containing eluted proteins were collected and analyzed using SDS-PAGE. The concentration of the collected antibodies was measured using the Bradford assay (19). To confirm the presence of soluble scFvs, the final products of purification were subjected to immunoblotting. The purified proteins were immunoblotted as described earlier using HRP-conjugated anti-His tag antibody (Clone H-3, Santa Cruz Biotechnology).

\section{Results}

\section{Production of ScFv against EGFR dimerization domain}

To evaluate the success of panning procedure, scFv coding sequences were amplified and enzymatically digested, by BstM restriction enzyme, in a number of randomly selected bacterial colonies at the end of each round of panning. The results of PCR on a number of colonies from each round of panning indicated the success of panning enrichment and the selection of the colonies containing the insert. Fingerprinting results showed a uniform pattern from round one to three (Fig.2). 
Cell-ELISA was performed to confirm the reactivity of the produced ScFv to the dimerization domain of EGFR. The results showed an increased OD after stimulation of EGFR with EGF, indicating that specific phages against the EGFR increased along with panning rounds (Fig.3).

\section{In vitro inhibition of EGFR/HER2 dimerization by the scFv}

To test whether the produced scFvs can inhibit the dimerization of EGFR and HER2, dimerization inhibition test was performed. Following cell lysis, immunoblotting showed two bands of 180 and 360 $\mathrm{kDa}$, corresponding to the monomeric and dimeric receptors, respectively. Over subsequent rounds of panning, the intensity of monomer band was increased compared to that of the dimer band, indicating the ability of the selected scFv to inhibit receptor homodimerization. In the third round, the intensity of the monomer band significantly increased, indicating the proper function of scFvs. Also, no dimer band was observed in unstimulated samples, showing the importance of receptor stimulation and the exposure of the dimerization domain (Fig.4a). The same test was performed to show the ability the selected scFv to inhibit EGFR/HER2 heterodimerization, the results showed a minimal amount of EGFR/HER2 heterodimerization (Fig.4b) when compared with EGFR homodimerization state. Similarly, in this test the intensity of dimeric bands decreased, as the number of specific scFvs accumulated in the subsequent rounds of panning. It should also be noted that the selected scFvs were more effective to disrupt EGFR/HER2 heterodimerization than EGFR homodimerization

\section{Production and purification of phage free scFv}

To test whether phage-bound scFvs selected from the last round of panning could be efficiently secreted into the bacterial periplasmic space, in a phage-free from, E. colistrain HB2151 was transduced with the phages from the third round of panning. Following induction of the bacteria with IPTG at $30^{\circ} \mathrm{C}, \mathrm{a}$ significant expression of phage-free scFv was detected on SDS-PAGE (Fig.5A). The periplasmic fraction was then his-tag purified (Fig.5B) and confirmed via immunoblotting (Fig.5C).

\section{Discussion}

The ErbB family receptors take part in cell growth, survival, and differentiation; also, they have a leading role in the pathogenesis and metastasis of a variety of cancers (18). Activation of these receptors basically depends on dimerization (19) with binding of the receptor to its ligand activates the tyrosine kinase and then dimers with the same receptor, so-called homodimerization, or with another member of the family, so-called heterodimerization.

HER2, as an orphan receptor, could be activated via homodimerization, alternatively, heterodimerization with EGFR or HER3, although no tyrosine kinase activity has been recognized for HER3 (20). Once the receptor is inactive or ligand-free, the dimerization arm is hidden by intramolecular interactions, so-called "tethered configuration" (21). Mutation in both the extracellular region and the kinase domain of the EGFR 
can lead to its activation and dimerization (22). Several ligands have been found for EGFR, such as EGF, transforming growth factor $a$, amphiregulin, betacellulin, epiregulin, and heparin binding-EGF (23).

In this study, we produced scFvs against the domain II (dimerization domain) of EGFR to block its homoand also hetero-dimerization with HER2. We used EGFR expressing cell lines to select scFvs from a phage display library. When using a cell line as a source of antigen to select phages from a library, non-specific bindings could increase the background, since cell lines express many unrelated antigens (24). To reduce the background, panning was performed in two steps, first with MDA-MD-468, and then with VERO/EGFR cells.

So far, several mAbs have been developed against EGFR and HER2 receptors. Cetuximab is a murine/human chimeric antibody against the extracellular domain of EGFR, which blocks EGF binding and its downstream signaling pathway. Despite its beneficial effects, it showed resistance in some cancers, such as triple-negative breast cancer, due to its partial agonistic effect on EGFR (25). Later on, panitumumab, a fully human mAb against the extracellular domain of EGFR, was developed and approved by the FDA for the treatment of colorectal cancer. Panitumumab could bind to a different epitope from the receptor to solve the problem of resistance. However, as an antagonist for EGF, it induces EGFR internalization (12). Pertuzumab, a humanized antibody against dimerization domain of HER2, specifically inhibits both HER2 homodimerization and its heterodimerizarion with EGFR and preferentially with HER3 $(20,26)$. Unlike mAbs mentioned above, the scFv produced in our study has been developed against the EGFR dimerization domain which can significantly reduce the problem of drug resistance in breast cancer.

It has been shown that HER2 positive tumors, such as breast tumors, had poorer prognosis when coexpress EGFR or when express a phosphorylated form of HER2 (27). The phosphorylated form of EGFR has also been found in breast tumors (28). The prognostic value of EGFR has been remarkable in both HER2 positive and estrogen and progesterone receptor-negative breast tumors (29). Therefore, targeting EGFR could be helpful in treating cancers overexpressing HER2. The scFv produced in our study could inhibit EGFR dimerization which makes it beneficial to treat triple-negative breast cancers that do not express HER2.

Trastuzumab is known as the first line of treatment in breast cancer; however, it could not inhibit signal transduction of HER2 receptor, because other receptors, particularly EGFR and HER3 can compensate the signaling leading to drug resistance (30). Pertuzumab is able to alleviate trastuzumab resistance to some extent, since it binds to a different domain of HER2 and mainly inhibits HER2/HER3 heterodimerization (31). In addition, EGFR has been shown to play an important role in signaling in breast tumor cells, especially HER2-positive tumors, makes it a crucial therapeutic target. In this study, we produced an scFv that can bind the dimerization domain of EGFR and HER2. The ErbB family receptors extracellular domain consists of four parts (IIV) with the dimerization domain (II) is hidden (32). For EGFR activation, first the domain II should be exposed, and then binds to its ligand (33). Therefore, the domain II is crucial for binding to other receptors and EGFR activation, while other domains are needed to stabilize the 
dimerization arm and receptor structure (33). In our study, using a phage display library, we developed an scFv which is able to inhibit the dimerization domain of EGFR and HER2. A big problem with phage display technique is the proliferation of non-specific clones; therefore, we used subtractive panning and receptor stimulation to select ScFvs with the highest specificity for the dimerization domain of EGFR. First, we performed a negative selection with MDA-MB-468 cells, and then; we stimulated the genetically engineered cell line, VERO/HER1/HER2, that only expresses HER1 and HER2 receptors to exposure dimerization arm and made a positive selection.

Phage display, using large combinatory antibody libraries, is a powerful method for producing customized antibodies against conformation-specific antibodies (34). ScFvs have some advantages over full-length mAbs. Due to their small size, scFvs could be easily produced and effectively enter the tumor microenvironment. Moreover, lacking the Fc region allows the scFvs to bind to their targets without stimulating the host's immune system, although this shortens their lifespan and thus requires a higher dosage of administration (35). Several scFvs have been tested in clinical trials, and some are FDAapproved, such as ScFv for TNF-a (36) and Brolucizumab, a humanized scFv against vascular endothelial growth factor A (VEGF-A), which has been FDA-approved for the treatment of wet age-related macular degeneration (37).

\section{Conclusions}

Up to now, at least 14 mAbs have been developed using the phage display method which approved by the FDA (38). In this study, we produced a scFv against the dimerization domain of EGFR. Further studies are needed to evaluate its in vitro and then in vivo functions, via functional assays, to test whether it can be used in diagnosis and treatment. Moreover, production of a whole mAb against dimerization domain of EGFR should be considered in the future.

\section{Declarations}

\section{Acknowledgments}

This study was supported by the Molecular and Cell Biology Research Center (MCBRC), Mazandaran University of Medical Sciences, Sari, Mazandaran, Iran (grant number 1658), and a grant from the Iranian National Science Foundation (INSF 91002930). Also, we would like to pay our great respects to our deceased colleague Dr. Mohammad Reza Bassami. This work is dedicated to his memory.

Funding: This study was supported by the Molecular and Cell Biology Research Center (MCBRC), Mazandaran University of Medical Sciences, Sari, Mazandaran, Iran (grant number 1658), and a grant from the Iranian National Science Foundation (INSF 91002930).

Conflicts of interest/Competing interests: The authors declare that the research was conducted in the absence of any commercial or financial relationships that could be construed as a potential conflict of interest. 
Availability of data and material: The authors confirm that the data supporting the findings of this study are available within the article.

Code availability: Graphpad prism 8

Authors' contributions: Not applicable

Ethics approval: The Research Ethics Committee has confirmed that no ethical approval is required.

Consent to participate: Informed consent was obtained from all individual participants included in the study.

Consent for publication: I, the undersigned, give my consent for the publication of identifiable details, which can include a photograph(s) and/or videos and/or case history and/or details within the text ("Material") to be published in the Applied Biochemistry and Biotechnology Journal.

\section{References}

1. Wang, C., Wang, L., Yu, X., Zhang, Y., Meng, Y., Wang, H., et al. (2017). Combating acquired resistance to trastuzumab by an anti-ErbB2 fully human antibody. Oncotarget, 8(26), 42742-42751.

2. Nahta, R., \& Esteva, F. J. (2006). HER2 therapy: molecular mechanisms of trastuzumab resistance. Breast Cancer Res, 8(6), 215-.

3. Yarden, Y., \& Sliwkowski, M. X. (2001). Untangling the ErbB signalling network. Nature reviews Molecular cell biology, 2(2), 127-137.

4. Burgess, A. W. (2008). EGFR family: Structure physiology signalling and therapeutic targetst. Growth Factors, 26(5), 263-274.

5. Appert-Collin, A., Hubert, P., Crémel, G., \& Bennasroune, A. (2015). Role of ErbB Receptors in Cancer Cell Migration and Invasion. Frontiers in Pharmacology, 6, 283-.

6. Wieduwilt, M. J., \& Moasser, M. M. (2008). The epidermal growth factor receptor family: biology driving targeted therapeutics. Cell Mol Life Sci, 65(10), 1566-1584.

7. Jacobi, N., Seeboeck, R., Hofmann, E., \& Eger, A. (2017). ErbB Family Signalling: A Paradigm for Oncogene Addiction and Personalized Oncology. Cancers (Basel), 9(4), 33.

8. Earp, H. S., Dawson, T. L., Li, X., \& Yu, H. (1995). Heterodimerization and functional interaction between EGF receptor family members: a new signaling paradigm with implications for breast cancer research. Breast cancer research and treatment, 35(1), 115-132.

9. Callahan, R., \& Hurvitz, S. (2011). Human epidermal growth factor receptor-2-positive breast cancer: Current management of early, advanced, and recurrent disease. Curr Opin Obstet Gynecol, 23(1), 3743.

10. Wahler, J., \& Suh, N. (2015). Targeting HER2 Positive Breast Cancer with Chemopreventive Agents. Curr Pharmacol Rep, 1(5), 324-335. 
11. Martini, G., Ciardiello, D., Vitiello, P. P., Napolitano, S., Cardone, C., Cuomo, A., et al. (2020). Resistance to anti-epidermal growth factor receptor in metastatic colorectal cancer: What does still need to be addressed? Cancer Treatment Reviews, 86, 102023.

12. García-Foncillas, J., Sunakawa, Y., Aderka, D., Wainberg, Z., Ronga, P., Witzler, P., et al. (2019). Distinguishing Features of Cetuximab and Panitumumab in Colorectal Cancer and Other Solid Tumors. Front Oncol, 9, 849-.

13. Salimi, F., Forouzandeh Moghadam, M., \& Rajabibazl, M. (2018). Development of a novel anti-HER2 scFv by ribosome display and in silico evaluation of its 3D structure and interaction with HER2, alone and after fusion to LAMP2B. Molecular biology reports, 45(6), 2247-2256.

14. Ahmad, Z. A., Yeap, S. K., Ali, A. M., Ho, W. Y., Alitheen, N. B. M., \& Hamid, M. (2012). scFv antibody: principles and clinical application. Clin Dev Immunol, 2012, 980250-.

15. Hedayatizadeh-Omran, A., Valadan, R., Rafiei, A., Ajami, A., Tehrani, M., \& Alizadeh-Navaei, R. (2015). Generation of $\mathrm{CHO}$ Stable Cell Line Overexpressing HER2: an In Vitro Model for Breast Cancer. Research in Molecular Medicine, 3(3), 6-10.

16. Hedayatizadeh-Omran, A., Valadan, R., Rafiei, A., Tehrani, M., \& Alizadeh-Navaei, R. (2015). VERO stable cell lines expressing full-length human epidermal growth factor receptors 2 and 3: platforms for subtractive phage display. DNA and cell biology, 34(9), 573-578.

17. Hedayatizadeh-Omran, A., RA, Janbabaei, G., Ajami, A., Valadan, R., Alizadeh-Navaei, R., Tehrani, M., Omrani-Nava, V., \& Ahmadi, A. Production of antibodies against HER2 and HER3 receptors in breast cancer treatment and the superior effect of the synchronous blockade of these receptors. world cancer research journal. 2016.

18. Momeny, M., Esmaeili, F., Hamzehlou, S., Yousefi, H., Javadikooshesh, S., Vahdatirad, V., et al. The ERBB receptor inhibitor dacomitinib suppresses proliferation and invasion of pancreatic ductal adenocarcinoma cells. Cellular oncology (Dordrecht). 2019.

19. Ogoshi, Y., Shien, K., Yoshioka, T., Torigoe, H., Sato, H., Sakaguchi, M., et al. (2019). Anti-tumor effect of neratinib against lung cancer cells harboring HER2 oncogene alterations. Oncology Letters, 17(3), $2729-2736$.

20. Iqbal, N., \& Iqbal, N. (2014). Human Epidermal Growth Factor Receptor 2 (HER2) in Cancers: Overexpression and Therapeutic Implications. Mol Biol Int, 2014, 852748-.

21. Li, S., Schmitz, K. R., Jeffrey, P. D., Wiltzius, J. J., Kussie, P., \& Ferguson, K. M. (2005). Structural basis for inhibition of the epidermal growth factor receptor by cetuximab. Cancer cell, 7(4), 301-311.

22. Ferguson, K. M. (2008). Structure-based view of epidermal growth factor receptor regulation. Annu Rev Biophys, 37, 353-373.

23. DeFazio-Eli, L., Strommen, K., Dao-Pick, T., Parry, G., Goodman, L., \& Winslow, J. (2011). Quantitative assays for the measurement of HER1-HER2 heterodimerization and phosphorylation in cell lines and breast tumors: applications for diagnostics and targeted drug mechanism of action. Breast Cancer Research, 13(2), R44. 
24. Alfaleh, M. A., Jones, M. L., Howard, C. B., \& Mahler, S. M. (2017). Strategies for Selecting Membrane Protein-Specific Antibodies using Phage Display with Cell-Based Panning. Antibodies (Basel), 6(3), 10.

25. Gurdal, H., Tuglu, M. M., Bostanabad, S. Y., \& Dalkilic, B. (2019). Partial agonistic effect of cetuximab on epidermal growth factor receptor and Src kinase activation in triplenegative breast cancer cell lines. International journal of oncology, 54(4), 1345-1356.

26. Ho-Pun-Cheung, A., Bazin, H., Gaborit, N., Larbouret, C., Garnero, P., Assenat, E., et al. (2012). Quantification of HER expression and dimerization in patients' tumor samples using time-resolved Förster resonance energy transfer. PLoS One, 7(7), e37065-e.

27. DiGiovanna, M. P., Stern, D. F., Edgerton, S. M., Whalen, S. G., Moore, D. 2nd, Thor, A. D. (2005). Relationship of epidermal growth factor receptor expression to ErbB-2 signaling activity and prognosis in breast cancer patients. Journal of clinical oncology: official journal of the American Society of Clinical Oncology, 23(6), 1152-1160.

28. Koletsa, T., Kotoula, V., Karayannopoulou, G., \& Nenopoulou, E. EGFR expression and activation are common in HER2 positive and triple-negative breast tumours. Histology and histopathology. 2010.

29. Nieto, Y., Nawaz, F., Jones, R. B., Shpall, E. J., \& Nawaz, S. (2007). Prognostic significance of overexpression and phosphorylation of epidermal growth factor receptor (EGFR) and the presence of truncated EGFRvIII in locoregionally advanced breast cancer. Journal of clinical oncology, 25(28), 4405-4413.

30. Luque-Cabal, M., García-Teijido, P., Fernández-Pérez, Y., Sánchez-Lorenzo, L., \& Palacio-Vázquez, I. (2016). Mechanisms Behind the Resistance to Trastuzumab in HER2-Amplified Breast Cancer and Strategies to Overcome It. Clin Med Insights Oncol, 10(Suppl 1), 21-30.

31. Wang, J., \& Xu, B. (2019). Targeted therapeutic options and future perspectives for HER2-positive breast cancer. Signal Transduction and Targeted Therapy, 4(1), 34.

32. Dawson, J. P., Berger, M. B., Lin, C.-C., Schlessinger, J., Lemmon, M. A., \& Ferguson, K. M. (2005). Epidermal growth factor receptor dimerization and activation require ligand-induced conformational changes in the dimer interface. Molecular and cellular biology, 25(17), 7734-7742.

33. Elleman, T. C., Domagala, T., McKern, N. M., Nerrie, M., Lönnqvist, B., Adams, T. E., et al. (2001). Identification of a determinant of epidermal growth factor receptor ligand-binding specificity using a truncated, high-affinity form of the ectodomain. Biochemistry, 40(30), 8930-8939.

34. Paduch, M., Koide, A., Uysal, S., Rizk, S. S., Koide, S., \& Kossiakoff, A. A. (2013). Generating conformation-specific synthetic antibodies to trap proteins in selected functional states. Methods, 60(1), 3-14.

35. Bates, A., \& Power, C. A. (2019). David vs. Goliath: the structure, function, and clinical prospects of antibody fragments. Antibodies, 8(2), 28.

36. Geng, S., Chang, H., Qin, W., Lv, M., Li, Y., Feng, J., et al. (2015). A novel anti-TNF scFv constructed with human antibody frameworks and antagonistic peptides. Immunologic research, 62(3), 377385 . 
37. Nguyen, Q. D., Das, A., Do, D. V., Dugel, P., Gomes, A., Holz, F. G., et al. Brolucizumab: Evolution through Preclinical and Clinical Studies and the Implications for the Management of Neovascular AgeRelated Macular Degeneration. Ophthalmology. 2020.

38. Alfaleh, M. A., Alsaab, H. O., Mahmoud, A. B., Alkayyal, A. A., Jones, M. L., Mahler, S. M., et al. (2020). Phage Display Derived Monoclonal Antibodies: From Bench to Bedside. Frontiers in immunology, 11, $1986-$.

\section{Figures}

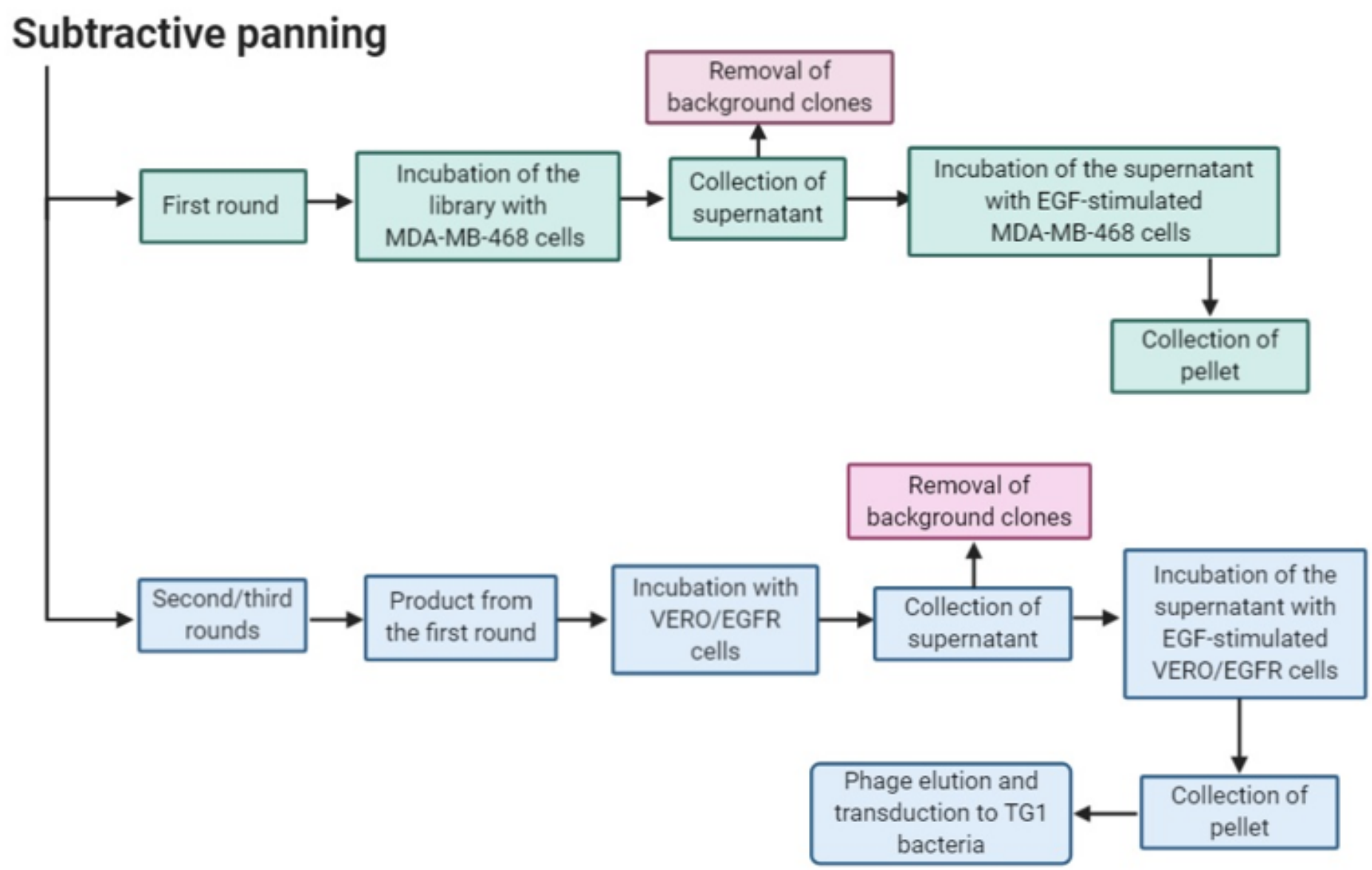

\section{Figure 1}

The process of selecting antibodies schematically. The general process used to produce ScFv against the EGFR receptor dimerization domain. To reduce the background, the first panning cycle was performed on MDA-MB-468 cells and then the other two cycles were performed using VERO/EGFR cells. 


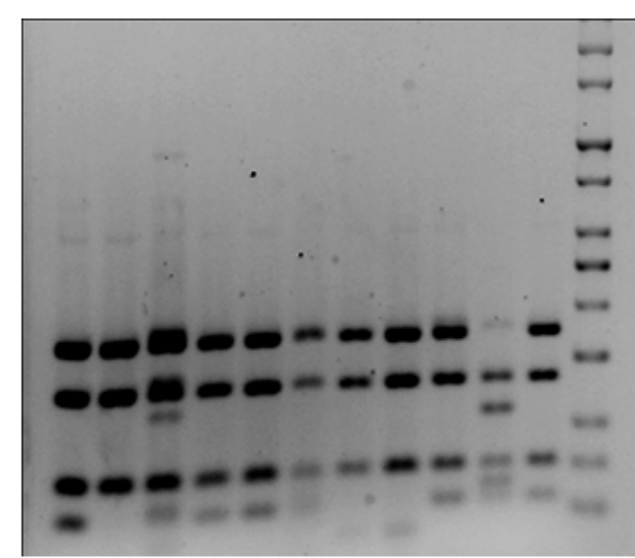

First round

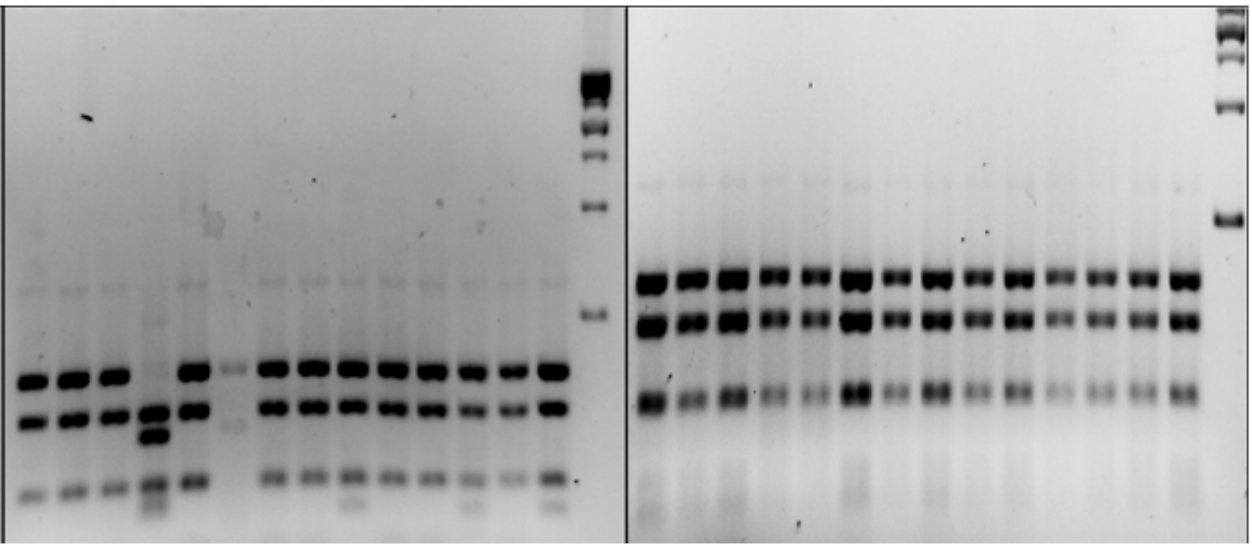

Second round
Third round

\section{Figure 2}

Fingerprinting results. Fingerprinting products of the first to third panning rounds. PCR products were cleaved by BstNI restriction enzyme and then loaded on agarose gel. After the third round, the enzymatic digestion pattern of the products became uniform.

\section{5}

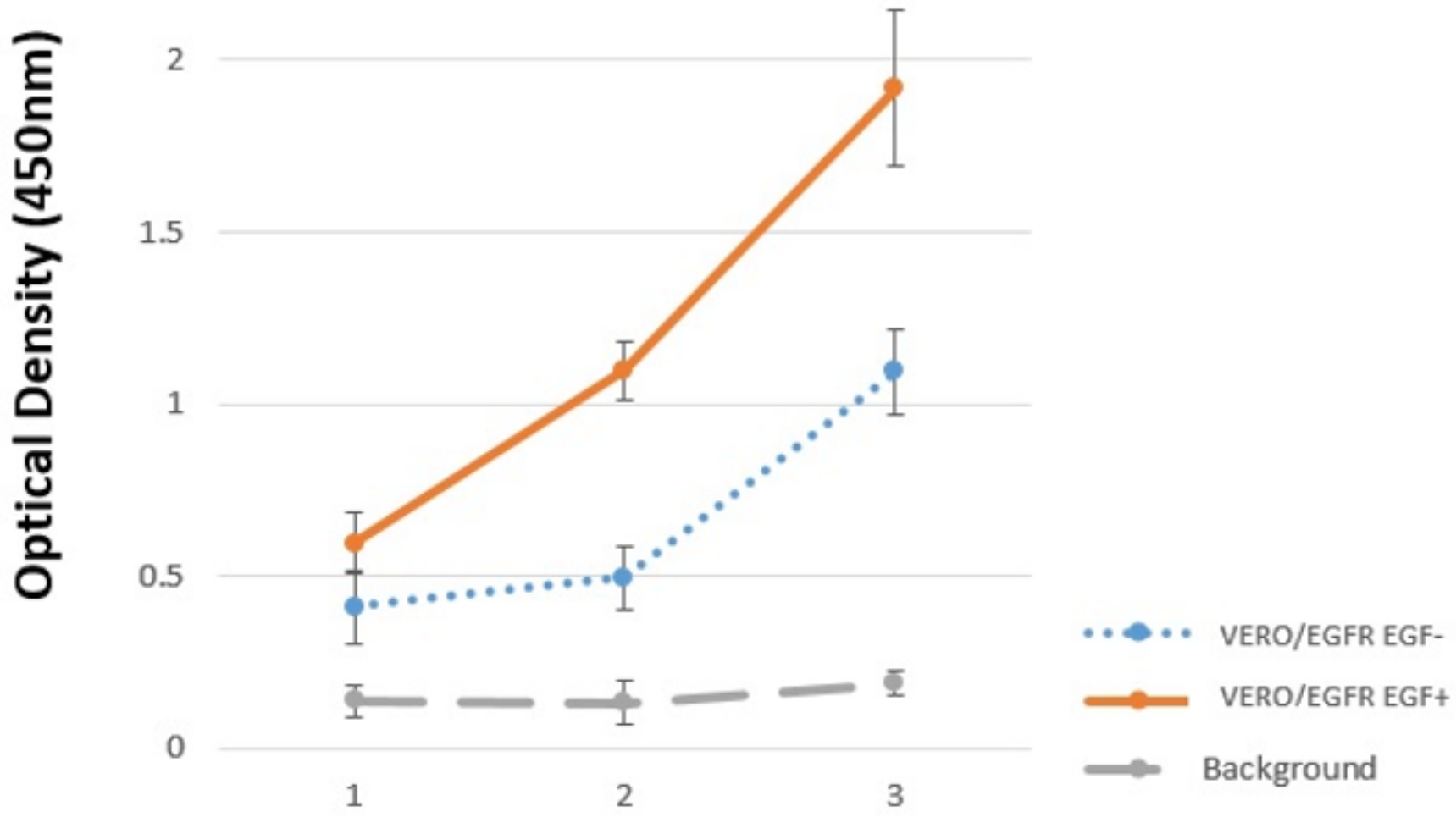

Rounds of Panning 


\section{Figure 3}

Polyclonal phage cell-ELISA results. OD of EGF-stimulated cells was increased over the three panning rounds. However, there was an increase in the third panning cycle in cells not stimulated by EGF due to an increase in the background.

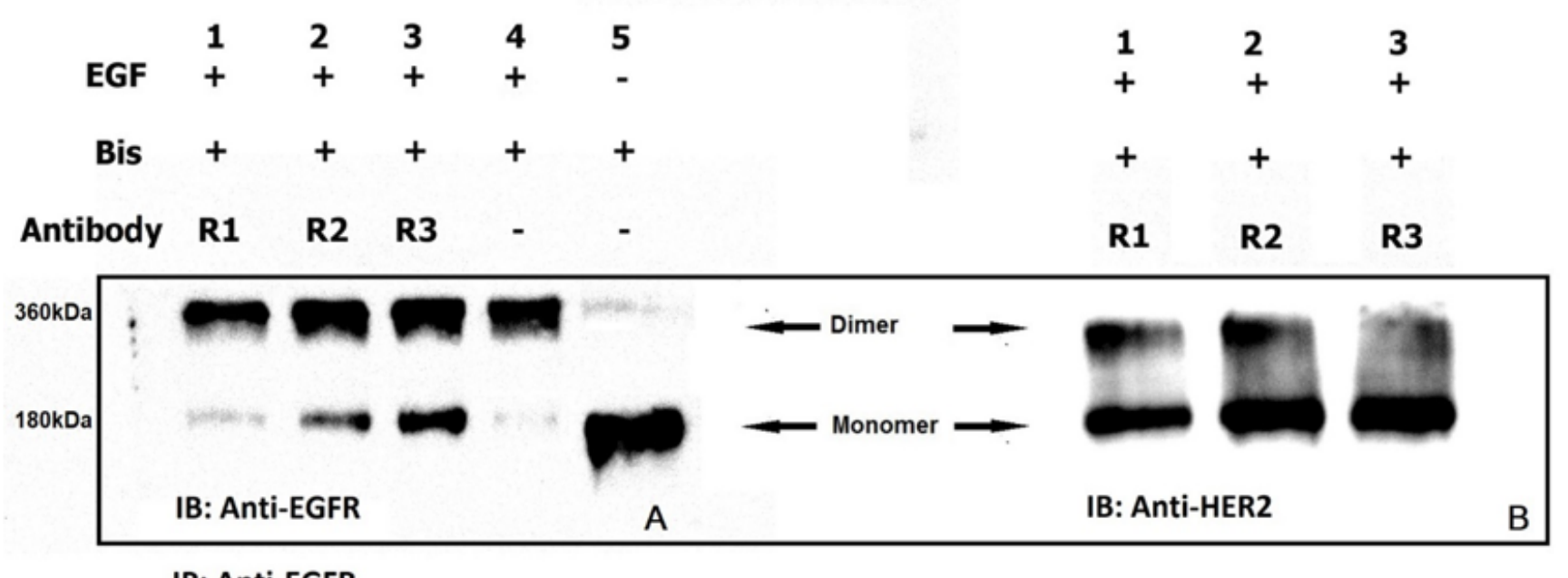

IP: Anti-EGFR

\section{Figure 4}

Dimerization inhibition test. (A) Incubation of different cycles of phages selection against the EGFR receptor dimerization domain inhibited the dimerization of EGFR and HER2 receptors. Maximum inhibition is observed in the third round, which indicates the predominance of specific clones against the dimerization domain. (B) Immunoblotting was performed with anti-HER2. The absence of a dimer band at number 3 indicates specific inhibition of the dimerization of EGFR and HER2 receptors.

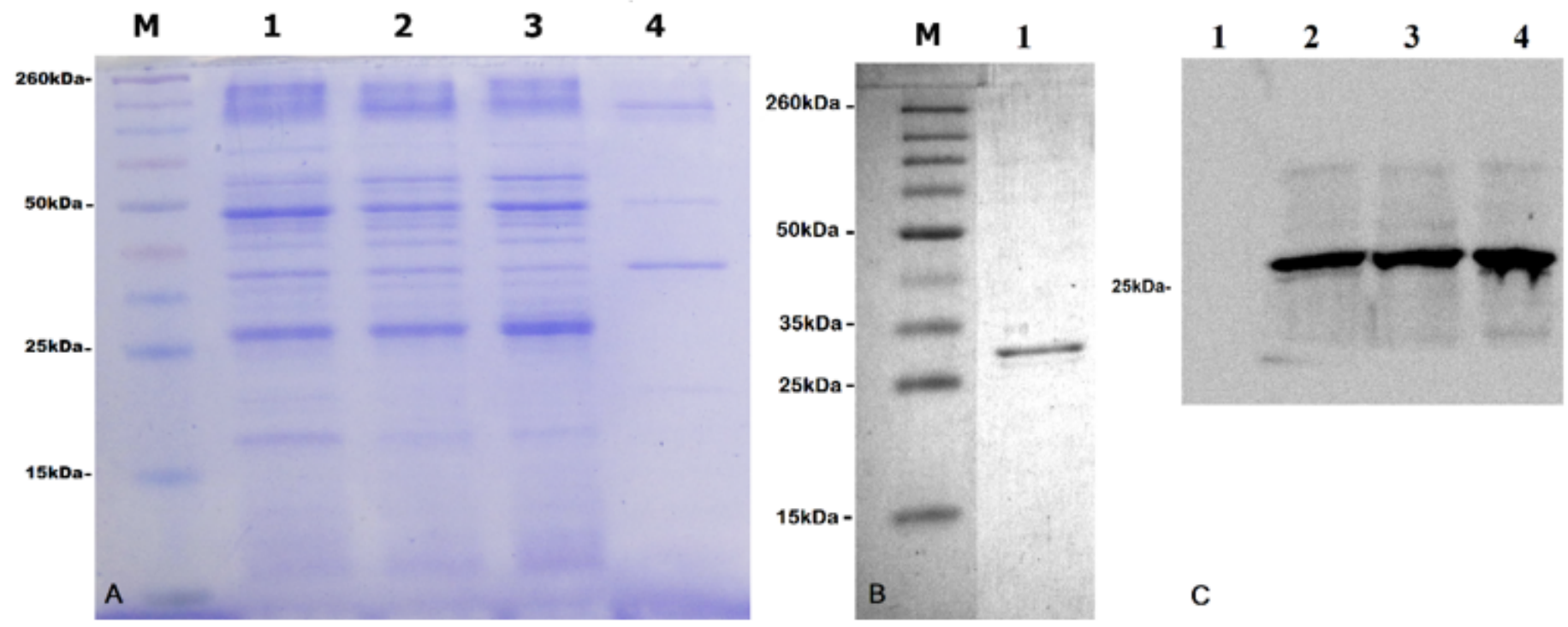




\section{Figure 5}

Production and purification of phage free scFv. (A) SDS-PAGE of bacterial lysate showing the expression of scFvs. Induction of antibody expression by IPTG in 3 samples (1 to 3 ) of panning cycles resulted in band expression of about $25 \mathrm{kDa}$. An example of an uninduced bacteria is given in column 4. (B) SDSPAGE of purified antibodies. Sample 1 extracted by His-Trap column and AKTA Purifier. (C) Immunoblotting of soluble antibodies produced in HB2151 bacteria. Three samples of antibody induced in HB2151 were evaluated by anti-His-tag antibody (number 2 to 4). A negative control sample containing uninduced bacteria has also been investigated (No. 1). 